\title{
An automated approach to measuring child movement and location in the early childhood classroom
}

\author{
Dwight W. Irvin ${ }^{1} \cdot$ Stephen A. Crutchfield ${ }^{2}$ - Charles R. Greenwood ${ }^{1}$. \\ William D. Kearns ${ }^{3}$ • Jay Buzhardt ${ }^{1}$
}

Published online: 8 June 2017

(C) Psychonomic Society, Inc. 2017

\begin{abstract}
Children's movement is an important issue in child development and outcome in early childhood research, intervention, and practice. Digital sensor technologies offer improvements in naturalistic movement measurement and analysis. We conducted validity and feasibility testing of a realtime, indoor mapping and location system (Ubisense, Inc.) within a preschool classroom. Real-time indoor mapping has several implications with respect to efficiently and conveniently: (a) determining the activity areas where children are spending the most and least time per day (e.g., music); and (b) mapping a focal child's atypical real-time movements (e.g., lapping behavior). We calibrated the accuracy of Ubisense point-by-point location estimates (i.e., $\mathrm{X}$ and $\mathrm{Y}$ coordinates) against laser rangefinder measurements using several
\end{abstract}

Dwight W. Irvin

dwirvin@ku.edu

Stephen A. Crutchfield

sacrutch@ calpoly.edu

Charles R. Greenwood

greenwood@ku.edu

William D. Kearns

kearns@usf.edu

Jay Buzhardt

jaybuz@ku.edu

1 Juniper Gardens Children's Project, University of Kansas, 444 Minnesota Avenue Ste. 300, Kansas City, KS 66101, USA

2 Department of Special Education, California Polytechnic State University at San Luis Obispo, 1 Grand Ave., San Luis Obispo, CA 93407, USA

3 Department of Rehabilitation and Mental Health Counseling, University of South Florida, 13301 N. Bruce B. Downs Blvd., Tampa, FL 33620, USA stationary points and atypical movement patterns as reference standards. Our results indicate that activity areas occupied and atypical movement patterns could be plotted with an accuracy of $30.48 \mathrm{~cm}$ ( $1 \mathrm{ft}$ ) using a Ubisense transponder tag attached to the participating child's shirt. The accuracy parallels findings of other researchers employing Ubisense to study atypical movement patterns in individuals at risk for dementia in an assisted living facility. The feasibility of Ubisense was tested in an approximately 90-min assessment of two children, one typically developing and one with Down syndrome, during natural classroom activities, and the results proved positive. Implications for employing Ubisense in early childhood classrooms as a data-based decision-making tool to support children's development and its potential integration with other wearable sensor technologies are discussed.

Keywords Real-time location system · Ubisense · Data-based decision making $\cdot$ Classroom location $\cdot$ Atypical movement

Since the passage of the Individuals with Disabilities Education Act (IDEA) in 1975 there has been ongoing interest in creating early childhood settings that include children with disabilities and yield positive developmental outcomes for all young children. Increasingly, early educators in their professional practice are expected to use data-based decision making for children with or at-risk for disabilities to monitor their developmental progress (Akers et al., 2015; US Departments of Health and Human Services and Education, 2015). Performing ongoing data collection is valuable in that it allows teachers to monitor children's progress and initiate specific interventions when children are not making developmental improvements, thereby ensuring kindergarten preparedness (Buzhardt, Walker, Greenwood, \& Heitzman-Powell, 2012). This paper introduces Ubisense ${ }^{\mathrm{TM}}$, a real-time location system 
(RTLS) that can be used to simultaneously identify multiple children's atypical movement patterns and tracks the activity areas they occupy as well as the time they spend in specific locations in the preschool classroom. With its ability to capture location and movement, RTLS potentially advances both early childhood research and teachers' and allied health service providers' (e.g., occupational therapist) ability monitor interventions while maximizing learning opportunities in the classroom.

Movement in children is a domain of child development (Gallahue \& Ozmun, 1995) and an outcome of early childhood research, intervention, and practice (Head Start, 2010; Hebbeler, Barton, \& Mallik, 2008; Priest et al., 2001). Locomotion has two functions: (1) mobility, getting from one place to another, and (2) exploration, discovering sources of needed environmental support and paths to them (Goldfield, 1995). Children's coordinated movement is needed in its own right, but also as an acquisition driver of other critically important skills including language, cognition, and social communication (Eliot, 1999; Piek, Dawson, Smith, \& Gasson, 2008; Shonkoff \& Phillips, 2000) and improved school readiness (Campos et al., 2000; Roebers et al., 2014; Zelazo, Carter, \& Reznick, 1997). The act of recording children's movement takes time and a certain amount of vigilance on the part of the human observer, whose potentially reactive presence might introduce an unwanted source of method variance. Until recently, video recording or direct observation have been the primary means to collect activity area data on young children frequent (e.g., Tapp, Wehby, \& Ellis, 1995) and discern movement patterns, both of which require substantial human resources limiting their access to practitioners.

Our proposed alternative uses automated RTLS to map indoor spatial and temporal coordinates of both young children in the classroom. Ubisense RTLS has demonstrated precision of 15-30 cm, depending upon local environmental conditions and the number of installed sensors - greater precision is achieved by applying more sensors (Kearns, Algase, Moore, \& Ahmed, 2008; Phebey, 2010; Woźniak, Odziemczyk, \& Nagórski, 2013). Ubisense RTLS was developed for industrial applications, specifically large vehicle assembly. The work of Kearns and colleagues has been critical in demonstrating this tool use for clinical purposes. This group has shown that this paricular RTLS is a valid approach to identifying individuals at risk for dementia via movement patterns (e.g., Kearns et al., 2008), and recently developed algorithms now allow for the identification and quantification of various types of atypical movement patterns in adults with dementia in a nursing home facility (Vuong, Chan, \& Lau, 2014). These researchers used Ubisense to better: (1) characterize cognitive impairment related to wandering behavior and fall risk in older residents in an assisted-living facility (Kearns, Nams, \& Fozard, 2010); (2) characterize the functional recovery patterns in veterans with traumatic brain injury (Kearns,
Scott, Fozard, Dillahunt-Aspillaga, \& Jasiewicz, 2016); and (3) support independent living by incorporating Ubisense into Smart Homes (Jasiewicz, Kearns, Craighead, Fozard, Scott, \& McCarthy, 2011). Although validity evidence exists for the rehabilitation context, it is not certain this tool would be feasible within early childhood settings because of: (1) the population in question (e.g., elderly adults vs. young children with and without disabilities); (2) uncertainty as to whether childcare staff and teachers would accept the system's placement and operation in the classroom (e.g., potential concerns about this type device being used as an evaluation tool); and (3) factors related to the industrial tag design (e.g., muffling a mild rattle emitted from the tag's trembler switch) and its placement on the body (e.g., the wrist of adults vs. the shoulder of the children).

Similar to adults with dementia, atypical locomotion may be a symptom of certain childhood disabilities (e.g., autism spectrum disorder (ASD), Down syndrome) (Hallett et al., 1993; Ozonoff et al., 2008) and may be negatively related to developmental outcomes essential for school readiness. Conceptually, atypical locomotion is a limitation in the control, planning and/or coordination of locomotor activity (Bhat et al., 2011). Atypical movement can be manifested in the form of lapping (Buggey, 2012), pacing (Bodfish, Symons, Parker, \& Lewis, 2000), or random movements (Crozier, \& Tincani, 2007), and may be displayed by young children with ASD, for example. Atypical movement in young children is developmentally significant because social and physical exploration is mediated via locomotion (Bhat et al., 2011; Campos, Anderson, Barbu-Roth, Hubbard, Hertenstein, \& Witherington, 2000), and therefore it may interfere with appropriate behaviors and, in turn, result in fewer opportunities to engage in social interactions that facilitate cognitive (Bhat et al., 2011) and social-communication skills (Berkeley, Zittel, Pitney, \& Nichols, 2001). While evidence exists that atypical movement affects young children's social learning opportunities, the tools to quantify and determine its relationship to cognitive and social-communication skills in natural contexts, such as classrooms, have been absent until now.

The classroom application of RTLS also promises to put a fresh lens on the activity arrangements made by teachers. Activity areas in early childhood classrooms ideally create geographically bounded regions for interacting with materials that support an array of developmental outcomes (Lawhon, \& Cobb, 2002; Montes \& Risley, 1975; Moore 1986) For example, "Books" area promotes literacy skills, "Manipulatives" area promotes fine motor skills, and "Science" area provides opportunities to increase reasoning/cognitive skills (Copple, \& Bredekamp, 2009). The ability to move among specific classroom activity areas and spend time in these activity areas is believed to selectively address core difficulties more so than others (i.e., support individualization) (e.g., Sontag, 1997), and classroom location data can assist teachers and 
researchers in designing optimal learning environments (McEvoy et al., 1991). For instance, it may be more important for a child with ASD to spend more time in activity areas that promote language and social engagement (e.g., more time in pretend play with peers) because of the social-communication and play limitations that accompany ASD. A child with Down syndrome may need to spend more time in activity areas that promote cognition (e.g., science) and gross motor development (e.g., outdoor play); areas in which these children often struggle. Evidence of this relationship has been reported in studies demonstrating specific classroom activity areas affecting the quality and quantity of interactions children with disabilities have with classroom peers and adults (Brown, Odom, Li, \& Zercher, 1999; File, 1994; Reszka, Odom, \& Hume, 2012). For example, when children with disabilities access activity areas with social toys (e.g., blocks), they are more likely to engage with peers than they are when they access areas with "isolate" toys (e.g., books) (Kim, Vaughn, Elbaum, Hughes, Sloan, \& Sridhar, 2003). Similarly, preschoolers with ASD are more than twice as likely to receive talk from classroom adults related to personal/practical assistance (e.g., "Do you need help finding the shovel?") in sensory/motor activity areas compared to large blocks/manipulatives activity areas (Irvin, Boyd, \& Odom, 2015). Although the above studies inform our understanding of the link between activity areas and children's development, they are limited in informing the actual practice of teachers. For example, it would be impractical for an educator to take valuable instructional time to observe and document children's time spent in each activity area over multiple days.

Clearly, young children's movement and the activity areas they occupy are factors affecting their development and, in turn, school readiness. Unfortunately, the way in which atypical movement and location are commonly measured may not inform a teacher's day-to-day practice. Movement can be measured via teacher report (e.g., Vineland Adaptive Behavior Scales [motor skills subscale]; Sparrow, Balla, \& Cicchetti, 2005), standardized measures (e.g., Movement Assessment Battery for Children; Henderson, \& Sugden, 1992) and/or with accelerometers (Lubans et al., 2011). Teacher report measures, although practical and authentic, have well documented limitations. For example, characteristics of teachers (e.g., years of experience) and features of classroom settings (e.g., adult-to-child ratio) are associated with teachers' perceptions of children's behaviors (Mashburn, Hamre, Downer, \& Pianta, 2006). Standardized measures can provide objective information on children's skill development relative to their peers. However, they require significant training, take time to administer and score, and create artificial scenarios that may or may not translate to natural settings for children with disabilities (e.g., Condouris, Meyer, \& Tager-Flusberg, 2003), and it may not be possible to administer them frequently enough to monitor progress (Greenwood, Carta, \& McConnell, 2011). Accelerometers measure the frequency or rate of change of movements but provide no information on the direction of the movement or the space in which the movement occurs (e.g., $\mathrm{x}$, $\mathrm{y}$ coordinates derived from the frame of reference for the behavior). From a classroom pedagogical perspective, this type of data does not provide information on where a child or a group of children actually move from or to, how long they stay in one location, the typical traffic patterns within the classroom, and whether or not a child's movement pattern is atypical. The data also do not inform the teacher how to better arrange and conduct classroom activities to achieve certain goals.

Eco-behavioral assessment provides a better means for defining the actual activity areas children with disabilities occupy and the time they spend in these locations, because it captures environmental features and behaviors through real-time observation (Carta, \& Greenwood, 1985; Odom, Favazza, Brown, \& Horn, 2000). However, eco-behavioral assessment: (1) often requires complex classifications of behaviors to be mastered by observers; (2) is typically based on short observational periods that may not be representative of the full school day; and (3) can entail human observers who may be deemed intrusive. Automated monitoring through wearable technology tools may address some of these concerns and improve the validity of ecological assessments (Goodwin, Velicer, \& Intille, 2008). With RTLS being limited in that it only captures location, and in turn locomotion, researchers may find eco-behavioral assessment a more robust approach given its ability to collect the data needed to determine relationships between location and other behaviors (e.g., child-peer talk, quality of engagement with materials) or if gross motor aptitude was of interest then a standardized measure (e.g., Peabody Scales of Motor Development, 2nd Ed.; Folio, \& Fewell, 2000) would likely be more appropriate. That said, behaviors of interest in the early childhood classrooms, such as child and adult talk, are increasingly being studied using automated approaches and could be linked with RTLS (e.g., Language ENvironmental Analysis [LENA] system; Irvin, Hume, Boyd, McBee, \& Odom, 2013) - discussed in the Future Research section. Compared to existing measurement approaches, RTLS technologies, such as Ubisense, offer several advantages for capturing the movements and time spent within activity areas for children with disabilities, including: (1) automated second-by-second location recordings across a full day; (2) quantitative estimates of multiple children's position, walking speed, and direction without the need for an observer; and (3) the possibility of near realtime feedback for teachers to inform them of their classroom management and instructional practices.

To our knowledge, this pilot investigation is the first to determine the validity of using RTLS in the early childhood classroom, a space where setting up the system has not been documented and participants (i.e., young children) 
acquiescing to wearing the device is not a given. RTLS has a proven history in industrial and health-service settings and is a robust technology. We postulate that RTLS applied to a preschool classroom will reveal undiscovered applications and efficiencies that could result in a data-based decision-making tool for early childhood teachers working in inclusive settings. More specifically, RTLS potentially enhances an early childhood teacher's ability to ensure that children with disabilities are spending adequate time in activities designed to prepare them for kindergarten. We tested RTLS in two important scenarios: (1) stationary positions in activity areas and (2) atypical movement patterns. We also examined whether the tool could be used with a child with and without a disability during naturally occurring activities in the preschool classroom. The key research questions addressed were: (1) what is the concordance of RTLS and laser rangefinder (LR) coordinates of a child in stationary positions and following atypical movement patterns in a preschool classroom; and (2) is it feasible to use RTLS with young children during naturally occurring activities in the early childhood classroom?

\section{Methods}

\section{Instrumentation}

Ubisense RTLS uses ultra-wideband radio to provide secondby-second, 3-D location simultaneously for up to 100 individuals in both outdoor and indoor environments; the analyzed RTLS data can yield location and movement pattern features and direction. The networked sensors and wearable lightweight transponder tags (see http://ubisense.net/en/products/ rtls-platform) relay data to a networked laptop or personal computer running the Ubisense Location Engine, which creates a digital map that monitors tag movements within the local environment. Ubisense RTLS is used in a variety of industrial settings (e.g., automotive, aviation, and petrochemical) to track assets (Phebey, 2010) and, as previously described, health services research (e.g., Kearns et al., 2010).

\section{Setting and participants}

The pilot investigation was conducted in an inclusive early childhood classroom. This classroom operated within a center-based program in a large urban community in the Midwest. The classroom measured approximately $12 \mathrm{~m}$ wide and $8 \mathrm{~m}$ in length, with extensions/cutouts for a small kitchen area and bathroom facilities (see Fig. 1 for classroom layout). Three consented children participated. One child (Julio) participated in the stationary and atypical movement accuracy tests when school was not in session to minimize distractions. Julio (pseudonym) was 5 years and 3 months old when he participated in the study and was typically developing. Two other preschool children (Thomas and Karen) participated in the feasibility testing on two separate school days during morning activities. Thomas (pseudonym) was 4 years and 9 months old when he participated in the study and had a medical diagnosis of Down syndrome. Karen (pseudonym) was 3 years and 1 month in age when she participated in the study

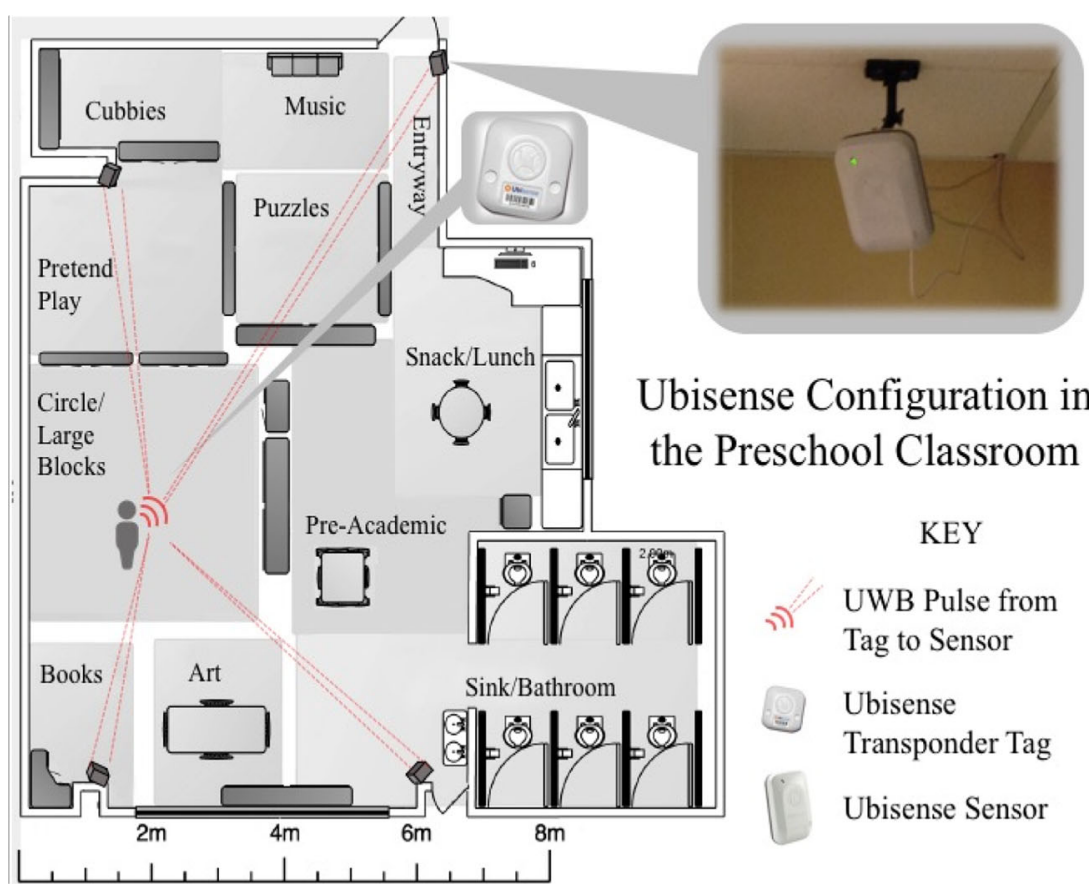

Fig. 1 Primary Ubisense components (i.e., tags and sensors) and their set-up in a preschool classroom 
and was typically developing. Caregivers completed a demographic survey to confirm any medical diagnosis.

\section{Procedures}

Our first step in this pilot investigation was to install the Ubisense Research Kit in the preschool classroom. The Research Kit consists of four sensors, mounting brackets and ten Series 7000 Compact Tags. The first and second authors of this pilot investigation received training on the use of the technology from a qualified Ubisense staff engineer before beginning installation. There are four key steps to setting up Ubisense: (1) accurately locating sensors in the four corners of the space to provide maximum coverage; (2) networking the sensors to a laptop computer; (3) minimizing electronic interference caused by other devices (i.e., Wi-Fi routers); and (4) precisely calibrating the RTLS sensors to their surveyed $\mathrm{x}, \mathrm{y}, \mathrm{z}$ locations using a LR.

To verify calibration, we placed a transponder tag on a tripod for $30 \mathrm{~s}$ and used a plumb-bob (i.e., weight suspended from a string) to align the tag with $8 \mathrm{LR}$ points throughout the classroom. Test results indicated an acceptable $13.7 \mathrm{~cm}$ mean difference between the tag and LR surveyed points. The next section describes accuracy tests for stationary and atypical movement pattern data obtained from the participating child. To identify the $\mathrm{x}$ and $\mathrm{y}$ coordinates, we again used a tripod with a plumb-bob as a guide to mark the specific floor location and then used the LR to obtain distance measures accurate to $\pm 1.59 \mathrm{~mm}$ with respect to the walls of the classroom. Based on recommendation of the Ubisense support engineer, we placed the transponder tag on the right shoulder of the children in a special pocket sewn on a comfortably fitting cotton t-shirt. The first and second authors ensured children habituated to wearing the t-shirt.

Stationary evaluation To test the ability of the RTLS to gather a child's stationary position accuracy in the classroom, we compared LR coordinates against RTLS coordinates in four activity areas of the preschool designated Art, Circle/large Blocks, Pre-academic, and Pretend play. These activity areas were chosen because: (1) they are common use areas in early childhood classrooms; and (2) they constitute distinct areas spanning the classroom space. Within each of the four activity areas we identified four sub-areas, so 16 stationary locations were measured in total. Once the coordinates were established for each sub-area, the child stood at the center of each location (marked with tape as an X on the floor) for $15 \mathrm{~s}$ while stationary estimates were obtained from the RTLS system.

Atypical movement evaluation To evaluate atypical movements, we used masking tape to form predefined trails on the floor (see Fig. 2) and asked the participating child to walk along these trails, five laps in total per pattern: lapping,

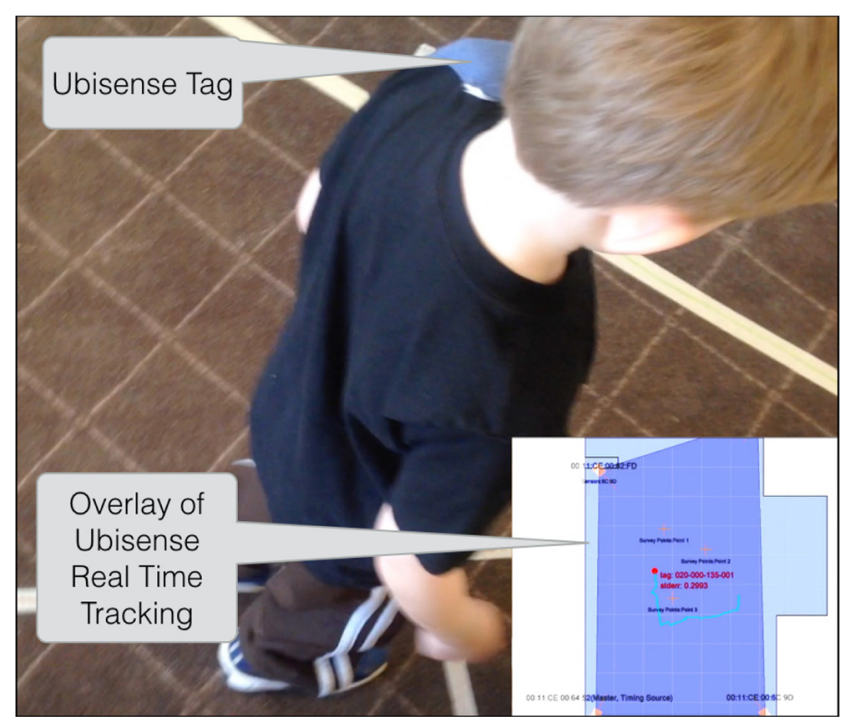

Fig. 2 Preschool-aged child wearing an Ubisense tag (within the pocket on his shoulder) and moving in the classroom. Inset depicts the Platform Control software tracking movement in real time

random, and pacing. Lapping can be conceptualized as circling an area in a repetitive manner, random is unplanned locomotion without repetition, and pacing is back-and-forth travel within small area (Martino-Saltzman, Blasch, Morris, \& McNeal, 1991). LR coordinates at 1-m intervals were taken to determine exact locations of specific points along the prescribed route. To make these intervals clearly visible on an accompanying direct-observation video, 60-cm segments of masking tape were placed perpendicularly along the taped route at specified intervals allowing an observer to visibly link the movement data with a known location. For each movement pattern, the camera operator cued Julio to begin walking the pattern at a normal pace.

Direct video observation of the child crossing the prespecified points was matched with corresponding RTLS data. RTLS scanning rate was $9 \mathrm{~Hz}$, yielding 8-10 location estimates/s while the video software (Finalcut $\mathrm{PRO}^{\mathrm{TM}}$ ) generated $30 \mathrm{frames} / \mathrm{s}$; we could therefore calibrate one source against the other (see Fig. 3 for a visual comparison of RTLS and camera intersection estimates for lapping behavior).

Data analysis For the stationary and movement data, the Pythagorean theorem Distance Formula (DF) $(d=$ sqrt [ $(x 1-$ $\left.\left.\mathrm{x} 2)^{2}+(\mathrm{y} 1-\mathrm{y} 2)^{2}\right]\right)$ was used to measure the discrepancy between the LR and RTLS location coordinates. For the stationary analysis, $15 \mathrm{~s}$ of RTLS coordinates for each sub-area within a given activity area were averaged (approximately 135 estimates) and compared against individual LR estimates. All DF calculations within each classroom sub-area were averaged to create a grand mean distance discrepancy between LR and RTLS measures in each classroom activity area (e.g., Art). For the atypical movement analysis, approximately 45 


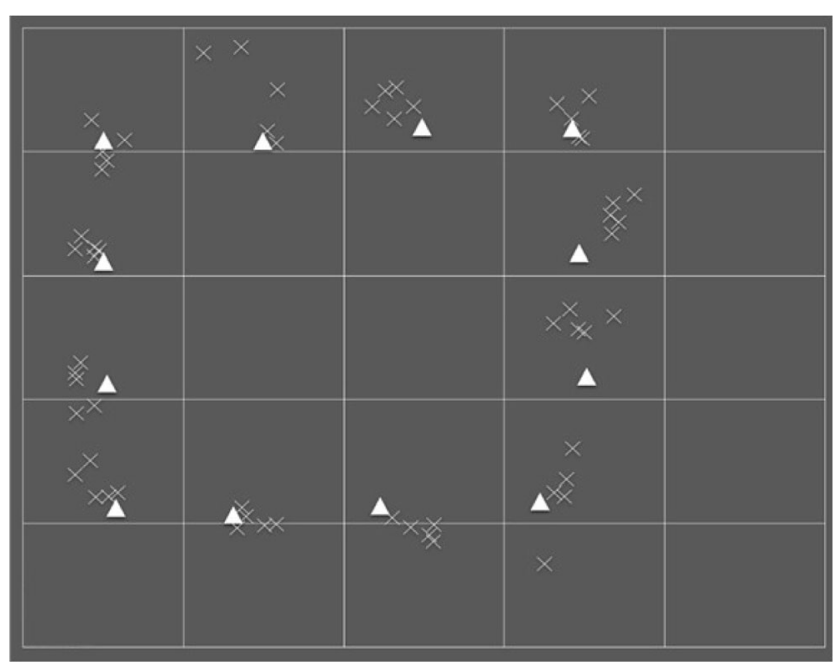

Fig. 3 Five rounds of lapping video-LR estimates compared to the RTLS estimates. Each square is $1 \mathrm{~m}$ in length and $\Delta \mathrm{s}$ represent video-LR intersections and Xs indicate RTLS point-by-point averages

RTLS estimates at each interval along the route were averaged and then compared to the LR coordinates associated with the synchronous video frame. All DF discrepancy calculations for each movement type were then averaged to create an average discrepancy for each atypical movement pattern (a measure of disagreement between the two location measures). With regard to natural classroom demonstration, the data presented reflect a roughly 90 -min recording span (5,400 1-s location estimates per child) during morning activities (e.g., free play, snack). Scanning rate was set to $1 \mathrm{~Hz}$ to increase the manageability of the large amount of data produced by the RTLS. The location estimates per second $(M=1.35)$ were averaged in order calculate time within activity areas. For participants, the location estimates were categorized by the $\mathrm{x}$, $\mathrm{y}$ coordinates of each classroom activity area via SPSS in order to determine the duration each participant spent in each classroom activity area.

\section{Results}

\section{Stationary estimates}

LR and RTLS measurements were recorded in a total of 16 sub-areas. Across all classroom areas the average difference in the distance between the LR and RTLS coordinates was 26.4 $\mathrm{cm}$. The standard deviation of all discrepancies between LR and RTLS measured points was $13.9 \mathrm{~cm}$. Of the 16 stationary locations, 12 fell within the standard range of precision $(<30$ $\mathrm{cm})$, three fell slightly outside this range $(30-40 \mathrm{~cm})$, and one data point (Pre-Academic 4) appeared to be an outlier with a value greater than $50 \mathrm{~cm}(51.8 \mathrm{~cm})$. See Table 1 for complete stationary results.
Table 1 Real-time location system (RTLS) vs. laser rangefinder (LR) discrepancies for stationary scenarios (units in meters)

\begin{tabular}{llllll}
\hline Activity areas & $\begin{array}{l}\text { Discrepancy } \\
\text { X X SD }\end{array}$ & $\begin{array}{l}\text { Discrepancy } \\
\text { Y }\end{array}$ & Y SD & DF \\
& & & & \\
\hline Circle/Large Blocks & 0.081 & 0.051 & 0.173 & 0.017 & 0.191 \\
$\quad$ 1 & & & & & \\
Circle/Large Blocks & 0.168 & 0.101 & 0.091 & 0.184 & 0.191 \\
$\quad$ 2 & & & & & \\
Circle/Large Blocks & 0.392 & 0.146 & 0.074 & 0.195 & 0.399 \\
3 & & & & & \\
Circle/Large Blocks & 0.028 & 0.102 & 0.348 & 0.128 & 0.348 \\
4 & & & & & \\
Circle/Large & $\mathbf{0 . 1 6 7}$ & $\mathbf{0 . 1 0 0}$ & $\mathbf{0 . 1 7 2}$ & $\mathbf{0 . 1 3 1}$ & $\mathbf{0 . 2 8 2}$ \\
$\quad$ Blocks GM & & & & & \\
Pretend Play 1 & 0.036 & 0.043 & 0.074 & 0.124 & 0.082 \\
Pretend Play 2 & 0.163 & 0.017 & 0.189 & 0.013 & 0.250 \\
Pretend Play 3 & 0.240 & 0.059 & 0.027 & 0.064 & 0.242 \\
Pretend Play 4 & 0.163 & 0.076 & 0.284 & 0.078 & 0.327 \\
Pretend Play GM & $\mathbf{0 . 1 5 0}$ & $\mathbf{0 . 0 4 9}$ & $\mathbf{0 . 1 4 4}$ & $\mathbf{0 . 0 7 0}$ & $\mathbf{0 . 2 2 5}$ \\
Pre-Academic 1 & 0.155 & 0.069 & 0.230 & 0.064 & 0.277 \\
Pre-Academic 2 & 0.237 & 0.096 & 0.075 & 0.097 & 0.249 \\
Pre-Academic 3 & 0.042 & 0.165 & 0.030 & 0.134 & 0.052 \\
Pre-Academic 4 & 0.011 & 0.166 & 0.518 & 0.221 & 0.518 \\
Pre-academic GM & $\mathbf{0 . 1 1 1}$ & $\mathbf{0 . 1 2 4}$ & $\mathbf{0 . 2 1 3}$ & $\mathbf{0 . 1 2 9}$ & $\mathbf{0 . 2 7 4}$ \\
Art 1 & 0.161 & 0.033 & 0.213 & 0.034 & 0.267 \\
Art 2 & 0.242 & 0.194 & 0.170 & 0.161 & 0.296 \\
Art 3 & 0.136 & 0.047 & 0.225 & 0.051 & 0.263 \\
Art 4 & 0.248 & 0.104 & 0.156 & 0.072 & 0.293 \\
Art GM & $\mathbf{0 . 1 9 7}$ & $\mathbf{0 . 0 9 5}$ & $\mathbf{0 . 1 9 1}$ & $\mathbf{0 . 0 8 0}$ & $\mathbf{0 . 2 8 0}$ \\
\hline & & & & & \\
\hline
\end{tabular}

Note. All estimates are in meters

$G M$ grand mean

\section{Atypical movement estimates}

The lapping pattern was $36 \mathrm{f}$. long (12-m intervals), the random pattern $27 \mathrm{f}$. (9-m intervals), and the pacing pattern was $12 \mathrm{f}$. (4-m intervals). The mean discrepancy across movement types was $23.9 \mathrm{~cm}$. The standard deviation of all atypical movement discrepancies was $11.8 \mathrm{~cm}$. Of the 25 movement estimates, 17 fell within the standard precision range $(<30$ $\mathrm{cm}$ ), five fell slightly beyond this range $(30-40 \mathrm{~cm})$, and three points were between 40 and $50 \mathrm{~cm}$. See Table 2 for complete atypical movement pattern results.

\section{Natural classroom demonstration}

Ubisense recorded for $90 \mathrm{~min}$ and there were approximately 7 min of missing data for each child, resulting in Thomas having 4,969 1-s location estimates and Karen 4,986. The small amount of missing data is likely related to the child briefly leaving the space. The distribution of time that Karen spent in classroom activity locations in descending rank order 
Table 2 Real-time location system (RTLS) vs. laser rangefinder (LR) discrepancies for atypical movement scenarios

\begin{tabular}{|c|c|c|c|}
\hline Atypical movement type & Discrepancy X & Discrepancy Y & $\mathrm{DF}$ \\
\hline Lapping 1 & 0.023 & 0.075 & 0.078 \\
\hline Lapping 2 & 0.240 & 0.314 & 0.396 \\
\hline Lapping 3 & 0.040 & 0.436 & 0.439 \\
\hline Lapping 4 & 0.128 & 0.040 & 0.134 \\
\hline Lapping 5 & 0.248 & 0.187 & 0.311 \\
\hline Lapping 6 & 0.121 & 0.043 & 0.129 \\
\hline Lapping 7 & 0.116 & 0.187 & 0.219 \\
\hline Lapping 8 & 0.165 & 0.023 & 0.167 \\
\hline Lapping 9 & 0.092 & 0.109 & 0.143 \\
\hline Lapping 10 & 0.012 & 0.063 & 0.065 \\
\hline Lapping 11 & 0.062 & 0.386 & 0.391 \\
\hline Lapping 12 & 0.183 & 0.197 & 0.269 \\
\hline Lapping GM & 0.119 & 0.171 & 0.228 \\
\hline Random 1 & 0.311 & 0.333 & 0.456 \\
\hline Random 2 & 0.145 & 0.028 & 0.148 \\
\hline Random 3 & 0.181 & 0.157 & 0.240 \\
\hline Random 4 & 0.165 & 0.218 & 0.273 \\
\hline Random 5 & 0.190 & 0.077 & 0.204 \\
\hline Random 6 & 0.053 & 0.223 & 0.229 \\
\hline Random 7 & 0.120 & 0.291 & 0.353 \\
\hline Random 8 & 0.123 & 0.077 & 0.144 \\
\hline Random 9 & 0.051 & 0.142 & 0.151 \\
\hline Random GM & 0.149 & 0.172 & 0.244 \\
\hline Pacing 1 & 0.023 & 0.075 & 0.078 \\
\hline Pacing 2 & 0.240 & 0.314 & 0.396 \\
\hline Pacing 3 & 0.040 & 0.436 & 0.439 \\
\hline Pacing 4 & 0.128 & 0.040 & 0.134 \\
\hline Pacing GM & 0.108 & 0.216 & 0.262 \\
\hline
\end{tabular}

Note. All estimates are in meters

$G M$ grand mean

ranged from $27.7 \mathrm{~min}$ in Circle/Large Blocks to no time at all in Daily Living (see Table 3). Thomas also spent most of his time in Circle/Large Blocks and much less in Daily Living even though the data were collected on different days. Overall, students spent similar amounts of time in a number of activities. However, Thomas in contrast to Karen spent a much greater amount of time in Pretend Play (22 min more) followed by Circle/Large Blocks ( 8 min more). Karen spent more time than Thomas in Art (19 min more) and PreAcademic (3 min more). Informally, we asked the lead teacher and each target child about any difficulties encountered in wearing the devices and no difficulties were reported.

Figure 4 is a heat map created via Excel Power Maps demonstrating the precise physical locations in which the two children spent time within specific activity areas: blue represents less time in a locations, while red areas indicate sites where the child spent more time. For example, Karen's map shows large
Table 3 Distribution of time spent in activity areas by two children on different days

\begin{tabular}{llll}
\hline Activity areas & $\begin{array}{l}\text { Thomas } \\
\text { minutes }\end{array}$ & $\begin{array}{l}\text { Karen } \\
\text { minutes }\end{array}$ & Difference \\
\hline 1. Circle/Large Blocks & 35.4 & 27.7 & -7.8 \\
2. Art & 0.9 & 19.8 & 18.9 \\
7. Music & 5.0 & 15.0 & 10.0 \\
5. Pre-Academic & 5.6 & 8.6 & 3.0 \\
6. Puzzles & 8.4 & 6.7 & -1.7 \\
11. Snack/Lunch & 2.6 & 2.7 & 0.1 \\
10. Entryway & 0.3 & 1.0 & 0.7 \\
8. Pretend Play & 22.6 & 0.9 & -21.8 \\
9. Cubbies & 0.4 & 0.5 & 0.2 \\
3. Books & 0.7 & 0.3 & -0.4 \\
4. Daily Living & 0.8 & 0.0 & -0.8 \\
\hline
\end{tabular}

Note. Data are sorted on Karen, the typically developing child

red location densities in activity areas 2 (Art) and 7 (Music) not seen in Thomas's map. Similarly, Thomas's heat map shows more red location densities in activity area 8 (Pretend Play). Other findings from the maps indicated both children spending little time in areas 4 (Daily Living), 9 (Cubbies), 10 (Entryway), and 11 (Snack/lunch). The detail in the geographical distribution of each individual's movement shown in Fig. 4 is not possible to see in the Table 3 numerical data. An additional impression of difference in movement between the two children is the much greater spatial diversity shown by Thomas in nearly each activity area (multiple blue dots) not nearly as evident in Karen's map. Additionally, visual inspection indicates Thomas has red location densities in about five areas, compared to eight for Karen. This suggests possible greater degrees of wandering (i.e., random movement) and lack of engagement within activity areas. Taken together, the numerical and visual data displays represent the kind of useful information that could be provided to teachers (and possibly parents and/or occupational and physical therapists) to quickly convey where children are spending their time in preschool, and whether or not it meets goals and expectations that each party might have regarding the services and instruction adults are planning and providing.

\section{Discussion}

This pilot investigation examined the use of RTLS as a means of identifying a child's atypical movement and the locations occupied in a preschool classroom. While the Ubisense system has been validated in other settings, it was not a given that results in the early childhood setting would be similar. The overall findings indicate that RTLS accurately located a young child within specific classroom activity areas and tracked 


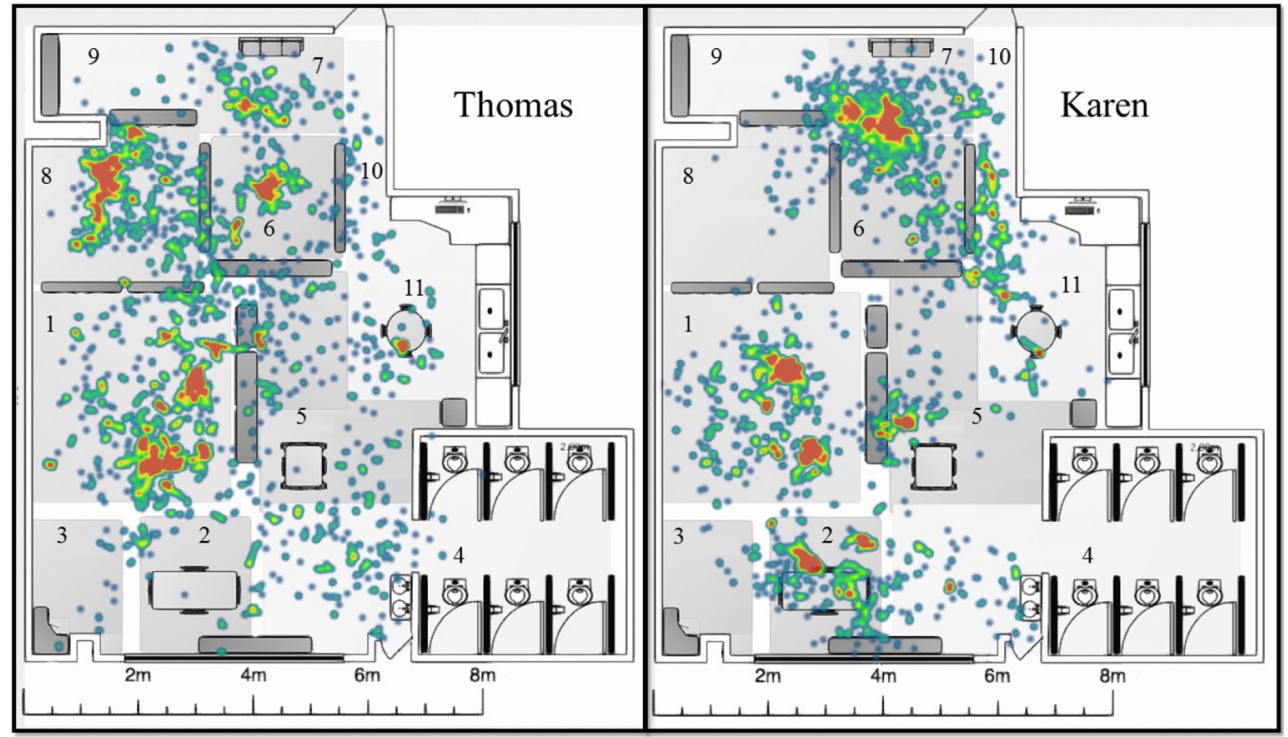

Fig. 4 Representation of the density of Ubisense location estimates for the two children. The key for the classroom activity areas is as follows: 1 = Circle $/$ Large Blocks; 2 = Art; 3 = Books; 4 = Daily Living; $5=$ Pre-

atypical movement patterns in the same manner within approximately $1 \mathrm{f}$. of a transponder tag $(<30 \mathrm{~cm})$. These results resemble those reported by Ubisense engineers (e.g., Phebey, 2010) as well as other independent researchers (e.g., Kearns et al., 2008) who have tested the RTLS technology in settings designed for adults. Further, this work demonstrates the feasibility of using RTLS in the preschool classroom. Not only was the RTLS technology accepted for use by the preschool administrator but consent was obtained from parents and assent from the child participants. As a first time investigation and proof of concept, the results strongly support the value of pursuing systematic investigations of yet unexplored issues in young children's classroom movement and instruction/ intervention.

Our stationary and atypical movement evaluation indicate overall the system functioned as intended; however, there were some data points for which error exceeded 30 $\mathrm{cm}$. The additional tracking error may have been due to the choice of location for the transponder tag on Julio. In order to achieve maximum exposure of the tag to the sensors and ensure a high degree of comfort for the child, the tag was enclosed in a specially designed external cloth pocket on the right shoulder of the child's t-shirt. This decision was made in part to isolate the tag from the child's body as RTLS accuracy suffers when body tissues absorb radio waves. However, placing the tag on the shoulder and away from the body's midline introduces a lateral offset relative to the LR point the child stood upon while stationary, or crossed during the atypical movement patterns. We contemplated measuring the distance from the child's midline to the tag and subtracting out this source of systematic error. However, having a preschool-
Academic; $6=$ Puzzles; $7=$ Music; $8=$ Pretend Play; $9=$ Cubbies; $10=$ Entryway; and $11=$ Snack/Lunch

aged child exactly align a transponder tag on his shoulder over each LDM stationary point and follow atypical movement patterns in the same manner was not possible, and would likely introduce additional error. This offset likely caused some of the Ubisense error estimates to exceed $30 \mathrm{~cm}$ in some scenarios (e.g., stationary evaluation: Pre-academic 4). Also, there were actions Julio was seen doing that may have affected the accuracy of the estimates. For example, he was observed resting his head on his shoulder, which might have temporarily occluded the tag and induced RTLS ranging errors.

Regarding the question of feasibility, classroom recordings of the two children clearly demonstrated that RTLS could be used in the natural context to detect 11 activity areas occupied by young children with and without disabilities as well as the time they spent in these locations (Table 3). Further, the heat map (Fig. 4) confirmed the numerical findings, adding enhanced clarity by illustrating the density and diversity of locations frequented. Importantly, the location differences of the two children were clearly demonstrated, as was the greater diversity and wider movement/scatter pattern of Thomas compared to Karen. If teachers were interested in whether a child was spending more time at the writing table versus counting with Pre-Academic, for example, these type of visual representations would be useful. These data indicate that the Ubisense RTLS can pinpoint student location and characterize atypical movement with acceptable accuracy in the early childhood space. Recent algorithmic investigations have shown that Ubisense RTLS coordinate data can be automatically identified as lapping, random, and pacing (Kumar, Lau, Chan, Ma, \& Kearns, 2016), which may 
simplify and advance the study of atypical movement patterns in school environments.

\section{Limitations}

There are several limitations to this study that need to be mentioned. First, the location data gathered during natural morning activities took place in the one classroom and included one child with and another without a disability, which limits our ability to generalize the findings. Because the data were sampled for each child on a different day, it was not clear what exactly might be accounting for the observed differences in locations. Was it due to child-centered differences related to disability status (Thomas) or simply a different schedule of activities on those days? Clearly, larger and more diverse samples of children sampled over more days is needed to understand children's movement patterns in the classroom. Another concern is the point that these pilot data were descriptive and not experimental. Thus, we cannot assume that our RTLS recorded differences in naturalistic activity locations either within or between children will be sensitive to planned or teacher manipulated changes in the classroom ecology, including instructions/commands to change locations. While we used video-based observation to test Ubisense accuracy detecting atypical movement patterns, we did not undertake identification of atypical movement patterns of an at-risk child in the natural classroom context. Doing so was beyond the scope of the current study, but a next step focus of future research.

\section{Future directions}

Researchers have long considered how size of classroom activity areas, materials and adaptations enhance or impede social and learning opportunities for young children with disabilities. However, the lack of real-time data has made these variables particularly challenging to study. RTLS could offer new insights on how materials within and the size of activity areas affect the time children spend in these locations and advance research on the physical ecology of the early childhood classroom (see Driscoll, \& Carter, 2004; Sainato et al., 2008). Ubisense has outdoor functionality and could also be used to measure how playground equipment adaptations at childcare centers support the participation of children with disabilities, such those with Down syndrome (e.g., Adamo, Wu, Wolery, Hemmeter, Ledford, \& Barton, 2015), which would likely be more robust than existing methods (i.e., direct observation or video coding).

Another logical extension of this work is to use the RTLS to validate existing measures of child movement. For example, the Early Movement Indicator (Carta, Greenwood, Walker, \& Buzhardt, 2010) and the Early Movement Monitoring Assessment (Leitschuh, Harring, \& Dunn, 2014) are observational progress-monitoring measures of infant and toddler growth in position change as well as horizontal and vertical locomotion, all of which can be captured by RTLS. Early identification of delay in movement skills can help to move children faster toward age-expected outcomes (Colombo, 2004; Lyon, 1996; Shonkoff \& Phillips, 2000). Ubisense may also assist in validating existing measures of repetitive and restrictive locomotion movements (e.g., Repetitive Behavior Scale-Revised; Bodfish, Symons, \& Lewis, 1999).

As described in the introduction, measuring atypical movement in young children is a challenging task given the current measurement tool options. Varying levels of akathisia (i.e., constant locomotion) (Tervo, Azuma, Fogas, \& Fiechtner, 2002) have been reported in young students with attention deficit hyperactivity disorder (ADHD), and bradykinesia (i.e., slowed movement) is visible in children with Down syndrome (Bhat et al., 2011; Latash, 2000; Vilensky, Damasio, \& Maurer, 1981). With children with some disabilities having fewer opportunities to engage in the social interactions, specific movement interventions (Donnellan, Hill, \& Leary, 2012; Srinivasan, \& Bhat, 2013) are employed to promote school readiness. For example, there is evidence that promoting social-communication skills can decrease lapping in children with ASD (Crozier, \& Tincani, 2007; Girolametto, Sussman, \& Weitzman, 2007). RTLS is a promising technique for both identifying and quantifying atypical movement as well as evaluating interventions used to ameliorate this behavior, particularly given newly advanced algorithms for capturing this type of behavior (e.g., Kumar et al., 2016; Vuong et al., 2014).

Clearly, this RTLS evaluation offers stand-alone benefits to the field of early childhood research; however, its use with other sensor technology will likely produce additional groundbreaking knowledge about the relationship between young children's early childhood classroom experiences and their development (Goodwin, Velicer, \& Intille, 2008). For example, our group has begun exploring the use of the Language ENvironmental Analysis (LENA) system in combination with Ubisense RTLS (Irvin, Crutchfield, Greenwood, Simpson, Sangwan, \& Hansen, 2017; Sangwan, Hansen, Irvin, Crutchfield, \& Greenwood, 2015). The LENA consists of a digital language processor and speech-processing software that allows for the assessment of adult word count, conversational turns, and child vocalizations (Greenwood, et al. 2011). The LENA can record up to $16 \mathrm{~h}$ of speech and is worn by the child in a specially designed t-shirt pocket. The marrying of LENA with RTLS will permit us to better understand the classroom language environment young children at-risk for or with disabilities encounter by allowing the study of not only when but where more/less language is occurring (e.g., Pretend Play vs. Art). Automated collection, processing, and reporting of these data to teachers could allow them to make more precise data-based decisions about their classroom setup and how 
to best support adult-child and child-peer interactions within activity areas.

Ubisense combined with LENA could also advance the measurement of therapeutic services young children with disabilities receive (e.g., speech language therapy, occupational therapy). Parent reports are often used to determine the services that young children with disabilities receive. However, the degree to which the dosage and intensity of these services affects children's interactions with others in natural contexts is largely unknown and could potentially be better understood with Ubisense and LENA. Taking this premise still further, combining LENA, Ubisense RTLS and other sensors such as the Microsoft Kinect ${ }^{\mathrm{TM}}$, a color camera of which uses infrared light to read depth, may allow the quantification of gestures (e.g., Luo \& Cheung, 2014) used by teachers and nonverbal young children. Gesture use is quite frequent with children who are nonverbal, and this information also could aid therapists in monitoring early classroom intervention efforts. As sensor technologies continue to rapidly emerge and mature, the impetus to use them to enhance early interventions and improve early childhood special education and other educational applications will continue to increase.

Taken together, RTLS automated collection, processing, and reporting of child movement data promises to allow teachers and allied health services providers (e.g., occupational therapists) to make more precise data-based decisions about classroom arrangements, identification of disabilities, and how best to support adult-child and child-peer interactions within activity areas. RTLS would afford early childhood researchers the ability to examine a number of key questions regarding evidence-based practices in early childhood. Confirmation of this promise awaits future research.

\section{References}

Adamo, E. K., Wu, J., Wolery, M., Hemmeter, M. L., Ledford, J. R., \& Barton, E. E. (2015). Using video modeling, prompting, and behavior-specific praise to increase moderate-to-vigorous physical activity for young children with Down syndrome. Journal of Early Intervention, 37(4), 270-285.

Akers, L., Del Grosso, P., Atkins-Burnett, S., Monahan, S., Boller, K., Carta, J., \& Wasik, B. A. (2015). Research brief-tailored teaching: The need for stronger evidence about early childhood teachers' use of ongoing assessment to individualize instruction. Research Brief OPRE Report \#2015-59. Washington, DC: Mathematica Policy Research.

Berkeley, S. L., Zittel, L. L., Pitney, L. V., \& Nichols, S. E. (2001). Locomotor and object control skills of children diagnosed with autism. Adapted Physical Activity Quarterly, 18(4), 405-416.

Bhat, S., Coleman, H. G., Yousef, F., Johnston, B. T., McManus, D. T., Gavin, A. T., \& Murray, L. J. (2011). Risk of malignant progression in Barrett's esophagus patients: Results from a large populationbased study. Journal of the National Cancer Institute, 103(13), 1049-1057.
Bodfish, J. W., Symons, F. J., Parker, D. E., \& Lewis, M. H. (2000). Varieties of repetitive behavior in autism: Comparisons to mental retardation. Journal of Autism and Developmental Disorders, 30(3), 237-243.

Bodfish, J. W., Symons, F. J., \& Lewis, M. H. (1999) The repetitive behavior scales (RBS). Western Carolina Center Research Reports.

Brown, W. H., Odom, S. L., Li, S., \& Zercher, C. (1999). Ecobehavioral assessment in early childhood programs: A portrait of preschool inclusion. Journal of Special Education, 33(3), 138-153.

Buggey, T. (2012). Video modeling for persons with autism. In P. Prelock \& R. McCauley (Eds.), Effective interventions for persons with autism (pp. 345-370). Baltimore, MD: Brookes.

Buzhardt, J., Walker, D., Greenwood, C. R., \& Heitzman-Powell, L. (2012). Using technology to support progress monitoring and databased intervention decision making in early childhood: Is there an app for that? Focus on Exceptional Children, 44(8), 1-20.

Campos, J. J., Anderson, D. I., Barbu-Roth, M. A., Hubbard, E. M., Hertenstein, M. J., \& Witherington, D. (2000). Travel broadens the mind. Infancy, 1, 149-219.

Carta, J. J., \& Greenwood, C. R. (1985). Eco-behavioral assessment: A methodology for expanding the evaluation of early intervention programs. Topics in Early Childhood Special Education, 5(2), 88-104.

Carta, J. J., Greenwood, C. R., Walker, D., \& Buzhardt, J. (2010). Using IGDIs: Monitoring progress and improving intervention results for infants and young children. Baltimore, MD: Brookes.

Colombo, J. (2004). Visual attention in infancy: Process and product in early cognitive development. In M. I. Posner (Ed.), Cognitive neuroscience of attention (pp. 329-341). New York, NY: Guilford.

Condouris, K., Meyer, E., \& Tager-Flusberg, H. (2003). The relationship between standardized measures of language and measures of spontaneous speech in children with autism. American Journal of Speech-Language Pathology, 12(3), 349-358.

Copple, C., \& Bredekamp, S. (2009). Developmentally appropriate practice in early childhood programs serving children from birth through age 8. Washington, DC: National Association for the Education of Young Children.

Crozier, S., \& Tincani, M. (2007). Effects of social stories on prosocial behavior of preschool children with autism spectrum disorders. Journal of Autism and Developmental Disorders, 37(9), 18031814.

Donnellan, A. M., Hill, D. A., \& Leary, M. R. (2012). Rethinking autism: Implications of sensory and movement differences for understanding and support. Frontiers in Integrative Neuroscience, 6, 1-11.

Driscoll, C., \& Carter, M. (2004). Spatial density as a setting event for the social interaction of preschool children. International Journal of Disability, Development and Education, 51, 7-37.

Eliot, L. (1999). What's going on in there? How the brain and mind develop in the first five years of life. New York: Bantam Books.

File, N. (1994). Children's play, teacher-child interactions, and teacher beliefs in integrated early childhood programs. Early Childhood Research Quarterly, 9(2), 223-240.

Folio, M. R., \& Fewell, R. R. (2000). Peabody developmental motor scales: Examiner's manual. Pro-ed.

Gallahue, D. L., \& Ozmun, J. C. (1995). Understanding motor development: Infants, children, adolescents, and adults (3rd ed.). Madison, WI: Brown \& Benchmark.

Girolametto, L., Sussman, F., \& Weitzman, E. (2007). Using case study methods to investigate the effects of interactive intervention for children with autism spectrum disorders. Journal of Communication Disorders, 40(6), 470-492.

Goldfield, E. C. (1995). Emergent forms: Origins and early development of human action and perception. New York: Oxford University Press.

Goodwin, M. S., Velicer, W. F., \& Intille, S. S. (2008). Telemetric monitoring in the behavior sciences. Behavior Research Methods, 40(1), 328-341. 
Greenwood, C. R., Carta, J. J., \& McConnell, S. (2011). Advances in measurement for universal screening and individual progress monitoring of young children. Journal of Early Intervention, 33(4), 254 267.

Hallett, M., Lebiedowska, M. K., Thomas, S. L., Stanhope, S. J., Denckla, M. B., \& Rumsey, J. (1993). Locomotion of autistic adults. Archives of Neurology, 50, 1304-1308.

Head Start. (2010). The Head Start child development and early learning framework promoting positive outcomes in early childhood programs serving children 3-5 years old: Revised. Retrieved from Retrieved August 1, 2011. Online at http://eclkc.ohs.acf.hhs.gov/ hslc/tta-system/teaching/eecd/Assessment/Child\%20Outcomes/ HS Revised Child Outcomes Framework.pdf

Hebbeler, K., Barton, L. R., \& Mallik, S. (2008). Assessment and accountability for programs serving young children. Exceptionality, 16, 48-63.

Henderson, S. E., \& Sugden, D. A. (1992). Movement assessment battery for children. London: Psychological Corporation.

Irvin, D. W., Boyd, B. A., \& Odom, S. L. (2015). Child and setting characteristics affecting the adult talk directed at preschoolers with autism spectrum disorder in the inclusive classroom. Autism, 19(2), 223-234.

Irvin, D. W., Crutchfield, S. A., Greenwood, C. R., Simpson, R. L., Sangwan, A., \& Hansen, J. H. L. (2017). Exploring classroom behavioral imaging: Moving closer to effective and data-based early childhood inclusion planning. Advances in Neurodevelopmental Disorders. doi:10.1007/s41252-017-0014-8

Irvin, D. W., Hume, K., Boyd, B. A., McBee, M. T., \& Odom, S. L. (2013). Child and classroom characteristics associated with the adult language provided to preschoolers with autism spectrum disorder. Research in Autism Spectrum Disorders, 7(8), 947-955.

Jasiewicz, J., Kearns, W. D., Craighead, J., Fozard, J. L., Scott, S., \& McCarthy, J. (2011). Smart rehabilitation for the 21st century: The Tampa Smart Home for veterans with traumatic brain injury. Journal of Rehabilitation Research and Development, 48(8), viixviii.

Kearns, W., Algase, D., Moore, D., \& Ahmed, S. (2008). Ultra wideband radio: A novel method for measuring wandering in persons with dementia. Gerontechnology, 7(1), 48-57.

Kearns, W. D., Nams, V. O., \& Fozard, J. L. (2010). Tortuosity in movement paths is related to cognitive impairment. Wireless fractal estimation in assisted living facility residents. Methods of Information in Medicine, 49, 592-598.

Kearns, W. D., Scott, S., Fozard, J. L., Dillahunt-Aspillaga, C., \& Jasiewicz, J. M. (2016). Decreased movement path tortuosity is associated with improved functional status in patients with traumatic brain injury. The Journal of Head Trauma Rehabilitation, 31(1), E13-E19.

Kim, A. H., Vaughn, S., Elbaum, B., Hughes, M. T., Sloan, C. V. M., \& Sridhar, D. (2003). Effects of toys or group composition for children with disabilities: A synthesis. Journal of Early Intervention, 25(3), 189-205

Kumar, A. Lau, C. T., Chan, S., Ma, M., \& Kearns, W. D. (2016). A unified grid-based wandering pattern detection algorithm. Paper presented at the $38^{\text {th }}$ Annual International Conference of the IEEE Engineering in Medicine and Biology Society (EMBC), Orlando, Florida.

Latash, M. L. (2000). Motor coordination in Down syndrome: The role of adaptive changes. In D. Elliott, D. Weeks, \& R. Chua (Eds.), Perceptual-motor behavior in Down syndrome (pp. 199-223). London: Human Kinetics.

Lawhon, T., \& Cobb, J. B. (2002). Routines that build emergent literacy skills in infants, toddlers, and preschoolers. Early Childhood Education Journal, 30(2), 113-118.
Leitschuh, C. A., Harring, J. R., \& Dunn, W. (2014). A monitoring tool of infant and toddler movement skills. Journal of Early Intervention, $36(1), 18-36$.

Lubans, D. R., Hesketh, K., Cliff, D. P., Barnett, L. M., Salmon, J., Dollman, J., ... Hardy, L. L. (2011). A systematic review of the validity and reliability of sedentary behaviour measures used with children and adolescents. Obesity Reviews, 12, 781-799.

Luo, Y., \& Cheung, S. C. (2014). Privacy-aware video interface for behavioral evaluation in naturalistic environment. Kentucky Innovation and Entrepreneurship Conference, Louisville, KY.

Lyon, G. R. (1996). The need for conceptual and theoretical clarity in the study of attention, memory, and executive function. In G. R. Lyon \& N. Krasnegor (Eds.), Attention, memory, and executive function. Paul Brookes: Baltimore, MD.

Martino-Saltzman, D., Blasch, B. B., Morris, R. D., \& McNeal, L. W. (1991). Travel behavior of nursing home residents perceived as wanderers and nonwanderers. The Gerontologist, 31(5), 666-672.

Mashburn, A. J., Hamre, B. K., Downer, J. T., \& Pianta, R. C. (2006). Teacher and classroom characteristics associated with teachers' ratings of prekindergartners' relationships and behaviors. Journal of Psychoeducational Assessment, 24(4), 367-380.

McEvoy, M. A., Fox, J. J., \& Rosenberg, M. S. (1991). Organizing preschool environments: Suggestions for enhancing the development/ learning of preschool children with handicaps. Topics in Early Childhood Special Education, 11(2), 18-28.

Montes, F., \& Risley, T. R. (1975). Evaluating traditional day care practices: An empirical approach. In Child and youth care forum (Vol. 4, No. 3, pp. 208-215). Netherlands: Springer.

Moore, G. T. (1986). Effects of the spatial definition of behavior settings on children's behavior: A quasi-experimental field study. Journal of Environmental Psychology, 6(3), 205-231.

Odom, S. L., Favazza, P. C., Brown, W. H., \& Horn, E. M. (2000). Approaches to understanding the ecology of early childhood environments for children with disabilities. In T. Thompson, D. Felce, \& F. Symons (Eds.), Behavioral observation: Technology and applications in developmental disabilities (pp. 193-214). Baltimore, MD: Brookes.

Ozonoff, S., Macari, S., Young, G. S., Goldring, S., Thompson, M., \& Rogers, S. J. (2008). Atypical object exploration at 12 months of age is associated with autism in a prospective sample. Autism, 12(5), $457-472$.

Phebey, T. (2010). The Ubisense assembly control solution for BMW. In RTLS in Manufacturing Workshop-RFID Journal Europe Live.

Piek, J., Dawson, L., Smith, L. M., \& Gasson, N. (2008). The role of early fine and gross motor development on later motor and cognitive ability. Human Movement Science, 27, 668-681.

Priest, J. S., McConnell, S. R., Walker, D., Carta, J. J., Kaminski, R., McEvoy, M. A., ... Shinn, M. R. (2001). General growth outcomes for children: Developing a foundation for continuous progress measurement. Journal of Early Intervention, 24(3), 163-180.

Reszka, S. S., Odom, S. L., \& Hume, K. A. (2012). Ecological features of preschools and the social engagement of children with autism. Journal of Early Intervention, 34(1), 40-56.

Roebers, C. M., Röthlisberger, M., Neuenschwander, R., Cimeli, P., Michel, E., \& Jäger, K. (2014). The relation between cognitive and motor performance and their relevance for children's transition to school: A latent variable approach. Human Movement Science, 33, 284-297.

Sainato, D. M., Jung, S., Salmon, M. D., \& Axe, J. B. (2008). Clasroom influences on young children's emerging social competence. In W. H. Brown, S. L. Odom, \& S. R. McConnell (Eds.), Social competence of young children: Risk, disability, and intervention (pp. 99 116). Baltimore, MA: Paul H. Brookes.

Sangwan, A., Hansen, J. H. L., Irvin, D. W., Crutchfield, S., \& Greenwood, C. R. (2015). Studying the relationship between physical and language environments of children: Who's speaking to 
whom and where? Signal Processing and Signal Processing Education Workshop (SP/SPE), pp 49-54.

Shonkoff, J. P., \& Phillips, D. A. (2000). From neurons to neighborhoods: The science of early childhood development. Washington, DC: National Academy Press.

Sontag, J. C. (1997). Contextual factors influencing the sociability of preschool children with disabilities in integrated and segregated classrooms. Exceptional Children, 63(3), 389-404.

Sparrow, S. S., Balla, D. A., \& Cicchetti, D. V. (2005). Vineland II: Vineland adaptive behavior scales. American Guidance Service.

Srinivasan, S., \& Bhat, A. (2013). The effect of robot-child interactions on social attention and verbalization patterns of typically developing children and children with autism between 4 and 8 years. Autism, 3, 111. doi:10.4172/2165-7890.1000111

Tapp, J., Wehby, J., \& Ellis, D. (1995). A multiple option observation system for experimental studies: MOOSES. Behavior Research Methods, Instruments, \& Computers, 27(1), 25-31.

Tervo, R. C., Azuma, S., Fogas, B., \& Fiechtner, H. (2002). Children with ADHD and motor dysfunction compared with children with ADHD only. Developmental Medicine and Child Neurology, 44(6), 383-390.
U.S. Departments of Health and Human Services and Education. (2015). Policy statement on inclusion of children with disabilities in early childhood programs. Retrieved from http://www2.ed.gov/about/ inits/ed/earlylearning/inclusion/index.html

Vilensky, J. A., Damasio, A. R., \& Maurer, R. G. (1981). Gait disturbances in patients with autistic behavior. Archives of Neurology, 38, 646-649.

Vuong, N. K., Chan, S., \& Lau, C. T. (2014). Automated detection of wandering patterns in people with dementia. Gerontechnology, 12(3), 127-147.

Woźniak, M., Odziemczyk, W., \& Nagórski, K. (2013). Investigation of practical and theoretical accuracy of wireless indoor positioning system Ubisense. Reports on Geodesy and Geoinformatics, 95(1), 36- 48 .

Zelazo, P. D., Carter, A., \& Reznick, J. S. (1997). Early development of executive function: A problem-solving framework. Review of General Psychology, 1, 198-226. 